\title{
Design Optimization of Loop Heat Pipes with Cylindrical Evaporator and Integral Reservoir for Space Application
}

\author{
Valeri V. Vlassov, Fabiano L. de Sousa, and Roger R. Riehl \\ Division of Space Mechanics and Control, National Institute for Space Research \\ Av. Dos Astronautas 1758, S.J. dos Campos, SP, Brazil, 12227-010 \\ vlassov@dem.inpe.br
}

\begin{abstract}
Design optimization of a LHP system for a space application is considered. The system is composed of the LHP itself, an interface with the heat source (saddle) and a radiator. The criterion is minimal system mass while meeting the operational requirements. The optimization is performed with simultaneous consideration of hot and cold conditions with respect to imposed heat loads to the evaporator and external heat fluxes over the radiator panel. The design parameters of the system optimized are the active length of the evaporator, internal and external diameters of the primary wick, volume and size of the reservoir, thickness and width of the saddle, diameters and tube thickness of the transport lines and condenser, length of the condenser, dimensions of the radiator panel and the amount of the LHP working fluid charged. The LHP mass and optimal design parameters are obtained for three working fluids: ammonia, propylene and acetone; a comparative study of the optimal mass characteristics is performed. Fixed parameters are the required values of transferred heat loads, incident external heat fluxes for the hot and cold cases, length of the transport lines, material and fluid properties. Constraints include temperature limits for the attached equipment and the capillary limits of the LHP. A special steady state mathematical model was developed for the calculation of the LHP performance parameters and a global search metaheuristic, called Generalized Extremal Optimization (GEO), is used as the optimization tool.
\end{abstract}

Keywords: Loop heat pipe, optimal design, mathematical model, generalized extremal optimization. PACS: $02.60 . \mathrm{Pn} ; 02.70 .-\mathrm{c}$.

\section{INTRODUCTION}

LHP technology for Space applications has been an object of extensive studies in recent years. Many different designs of LHPs and CPLs have been developed and tested, (Maydanik, 2005; Nikitkin and Cullimore, 1998; Goncharov and Kolesnikov, 2002; Ku, 1999) and such devices have been used as key apparatuses of thermal control of spacecrafts such as GLAS, EOS-Chemistry, GOES and SWIFT. While LHP technologies have reached a certain level of maturity, many issues still remain as subjects of intensive research. The reason lies in the complex behavior of the processes of heat and mass transfer in the elements of the two-phase loops. A quest for improvements in performance is also a permanent goal.

Nowadays, one of the important issues is the optimization of the LHP design. LHPs for space applications are developed and produced by several companies in USA, Europe and Russia. Intensive activities on LHP studies and fabrication have recently been started in China, Japan and Brazil. Usually the LHP design optimization is based on prior accumulated experience, experimental studies, intensive testing, verification, and results of in-flight behavior. Mathematical models of different levels of detailing and experimental validation provide auxiliary support for making the design decision. However no systematic procedures of design optimization based on such mathematical models have been developed up to now, by the authors' knowledge.

The main design parameters of the LHP have mutual and contradictory influence on the LHP performance, compactness and mass. Small pore sizes of the primary wick provide high capillary pumping, however, causes increased hydraulic resistance for the liquid flow through the wick. The thickness of the wick could be reduced in 
order to decrease the hydraulic losses; however it causes an increase in the back conductance. The last causes an increment in the pressure inside the evaporator core and reservoir (or compensation chamber) therefore an increased condenser length is needed to compensate this effect. Reduced transport line diameter leads to a lower LHP mass, however it causes an increase in the hydraulic losses. A bigger diameter for the evaporator could lead to a reduced thermal resistance to the attached equipment; therefore, a smaller radiator area may be enough to keep the equipment temperature within the required limits. However, the evaporator mass and amount of fluid needed will be increased. These interdependences between the LHP design variables demonstrate a relative freedom of design parameter choice and prove a possibility of optimization for obtaining gain on the device performance.

In this paper a first tentative of a systematic procedure for the LHP design optimization is presented. The main objectives therefore are to demonstrate the feasibility and effectiveness of the optimal design approach.

\section{MATHEMATICAL MODEL}

Several LHP mathematical models have been recently developed. For example, the models developed by Cullimore and Baumann (2000) for SINDA/Fluint fluid-thermal analyzer software, as well as Buz and Goncharov's model (2002) embedded in EASY2000 software. Besides, there are models developed by Kaya and Hoang (1999), as well as by Vlassov, Schlitt and Bondendieck (2003), Vlassov and Riehl (2005). The present model is extracted from the last cited model by simplification and transformation of the transient model to a steady state one. The reduction was performed mainly for the condenser-radiator assembly sub-model and the simplification assumptions are similar to ones used by Kaya and Hoang (1999) for their steady-state model. They are: fluid in reservoir is under saturation conditions; fluid temperatures in evaporator core and reservoir are equal; the mass and heat transfer through the wicks is realized only in radial direction; vapor exits the evaporator and enters condenser in saturation conditions.

The nodal representation of the LHP is shown in Figure 1.

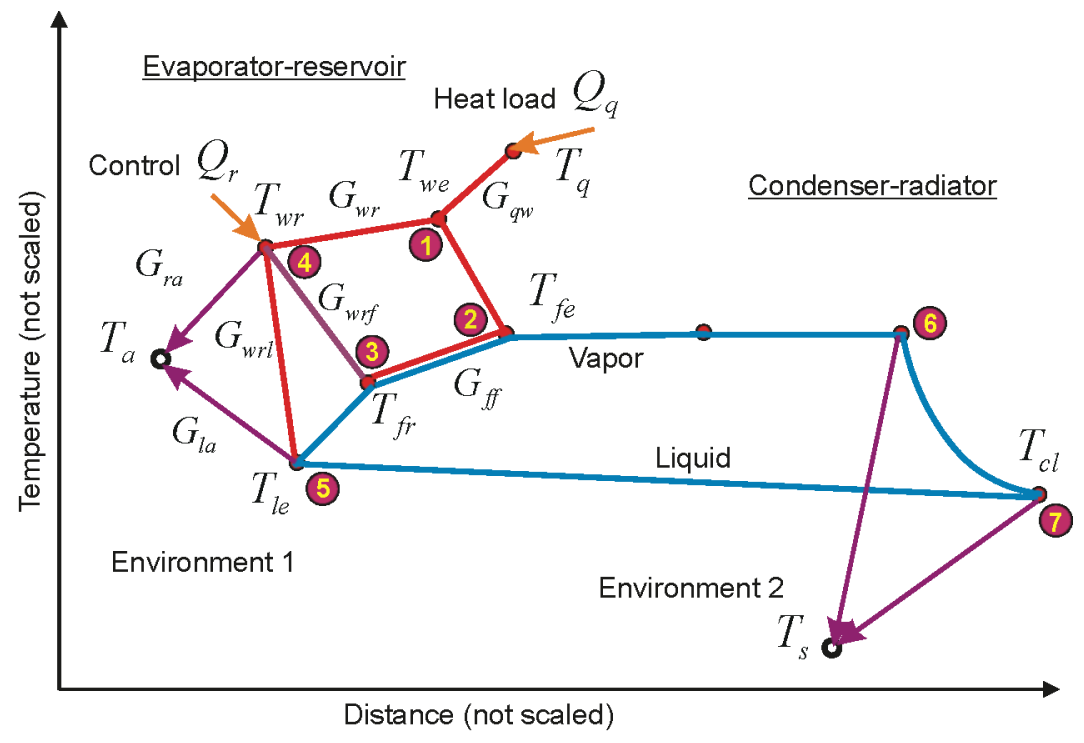

FIGURE 1. LHP Nodal Representation.

In each numbered node, the balance is formed by the sum of the entering and exiting flows of either heat or enthalpy, or both. The core set of equations describing the steady-state operation of the LHP is the following:

Node 1 (evaporator wall): $Q_{q}=G_{w r}\left(T_{w e}-T_{w r}\right)+G_{w f e}\left(T_{w e}-T_{f e}\right)$,

Node 2 (v/l interface in evaporator): $\quad G_{w f e}\left(T_{w e}-T_{f e}\right)=\lambda \dot{m}+G_{f f}\left(T_{f e}-T_{f r}\right)+C_{p} \dot{m}\left(T_{f e}-T_{f r}\right)$, 
Node $3\left(\right.$ v/l interface in reservoir) $\ldots G_{f f}\left(T_{f e}-T_{f r}\right)+G_{w f r}\left(T_{w r}-T_{f r}\right)+C_{p} \dot{m} T_{l e}=C_{p} \dot{m} T_{f r}$,

Node 4 (reservoir wall): $Q_{r}+G_{w r}\left(T_{w e}-T_{w r}\right)=G_{w f r}\left(T_{w r}-T_{f r}\right)+G_{w r l}\left(T_{w r}-T_{l e}\right)+G_{r a}\left(T_{w r}-T_{a}\right)$,

Node 5 (liquid line):.. $G_{w r l}\left(T_{w r}-T_{l e}\right)+G_{l a}\left(T_{a}-T_{l e}\right)+C_{p} \dot{m} T_{c l}=C_{p} \dot{m} T_{l e}$,

Node 6 (vapor line + condenser two-phase section): $\lambda \dot{m}+C_{p} \dot{m} T_{f e}=g_{c v a} \xi_{c o} L_{c}\left(T_{f e}-T_{s}\right)+C_{p} \dot{m} T_{f e}$,

Node 7 (condenser liquid section):... $C_{p} \dot{m} T_{f e}=C_{p} \dot{m} T_{c l}+g_{c l a}\left(1-\xi_{c o}\right) L_{c}\left(T_{c l}-T_{s}\right)$.

The equation set is closed by a hydraulic balance over the entire two-phase loop, coupled with the temperatures through the saturation conditions:

$$
P_{s a t}\left(T_{f e}\right)-P_{s a t}\left(T_{f r}\right)=\Delta P_{\Sigma}(\dot{m})
$$

where

$$
\Delta P_{\Sigma}(\dot{m})=\Delta P_{v}(\dot{m})+\Delta P_{l}(\dot{m})+\Delta P_{c v}\left(\dot{m}, \xi_{c o}\right)+\Delta P_{c l}\left(\dot{m}, \xi_{c o}\right)+\Delta P_{g}
$$

This set of non-linear equations is iteratively solved with respect to the following 8 unknowns:

$$
\bar{y}=\left\{\dot{m}, \xi_{c o}, T_{w e}, T_{w r}, T_{f e}, T_{f r}, T_{l e}, T_{c l}\right\} .
$$

The equipment temperature is calculated a posteriori as

$$
T_{q}=T_{w e}+Q_{q} G_{q w}^{-1}
$$

Linearization is used to calculate the radiation heat transfer; the effective sink temperature is defined as

$$
T_{s}=\sqrt[4]{\frac{\alpha_{S}\left(q_{S}+q_{A}\right)+\varepsilon q_{I R}}{\varepsilon \sigma}} .
$$

The radiation heat transfer coefficient is iteratively recalculated to adjust the vapor temperature $T_{f e}$ by:

$$
g_{c v a}=2 \varepsilon \sigma B_{c f} \eta_{f}\left(T_{f e}+T_{s}\right)\left(T_{f e}^{2}+T_{s}^{2}\right)
$$

For the liquid section of the condenser, the heat transfer coefficient is iteratively modified to account for the nonlinear temperature profile (rout 6-7 in Figure 1):

$$
\begin{aligned}
g_{c l a} & =\frac{C_{p} \dot{m}}{\left(1-\xi_{c o}\right) L_{c}}\left(\operatorname{Exp}\left(\frac{\left(1-\xi_{c o}\right) L_{c} \widetilde{g}_{c l a}}{C_{p} \dot{m}}\right)-1\right), \\
\widetilde{g}_{c l a} & =2 \varepsilon \sigma B_{c f} \eta_{f}\left(T_{c l}+T_{s}\right)\left(T_{c l}^{2}+T_{s}^{2}\right) .
\end{aligned}
$$

Node number 5 represents the whole liquid line; the parameter distributions along the tube could be tackled by the similar manner as for the liquid section of the condenser. However as it is assumed that the liquid line is covered with insulation, the profile of non-linearity does not produce significant influence, therefore average constant values can be accepted. The ambient temperature along the liquid line may undergo variations; in this case, averageintegral values may be used in the place of $T_{a}$ and $G_{l a}$ in Equation (5).

All generalized conductances $G_{i j}$ are functions of main dimensions and other parameters, such as: 


$$
\left\{\begin{array}{l}
G_{q w}=G_{q w}\left(L_{e}, H_{s d d}, \delta_{s d d}, B_{s d d}, D_{w e}, k_{s d d}\right) \\
G_{w r}=G_{w r}\left(L_{e}, L_{r}, D_{w e}, \delta_{w e}, k_{w e}, u_{j}\right) \\
G_{w f e}=G_{w f e}\left(L_{e}, H_{s d d}, D_{p w}, w_{w w}, w_{w v}, H_{w v}, k_{w e}, u_{j}\right) \\
G_{f f}=G_{f f}\left(L_{e}, D_{p w}, \delta_{w i c k}, k_{p}\right) \\
G_{w f r}=G_{w f r}\left(L_{r}, D_{w e}, \delta_{w e}, k_{w e}\right) \\
G_{w r l}=G_{w r l}\left(D_{t l}, \delta_{t l}, \delta_{w e}, D_{w e}, k_{w e}, u_{j}\right) \\
G_{l a}=G_{l a}\left(L_{t l}, D_{t l}, \delta_{t l}, k_{t l}, \delta_{i t l}, k_{i t l}, \varepsilon_{i t l}, h_{i t l, a}\right) \\
G_{r a}=G_{r a}\left(L_{r}, D_{w e}, \varepsilon_{r}, h_{r a}\right)
\end{array}\right.
$$

The conductances include also some uncertain parameters (set u), whose values should be first adjusted by experimental data (Vlassov and Riehl, 2005).

The main dimensions of the LHP are displayed in Figure 2. More details on the mathematical model can be found in other references (Vlassov and Riehl, 2005, 2006b). The evaporator contains a secondary wick wrapped on the bayonet tube, which passes through the integral reservoir (compensation chamber). The primary wick contains circumferential grooves and a unique vapor collector; details of the evaporator design and performance are given in (Riehl and Santos, 2006).

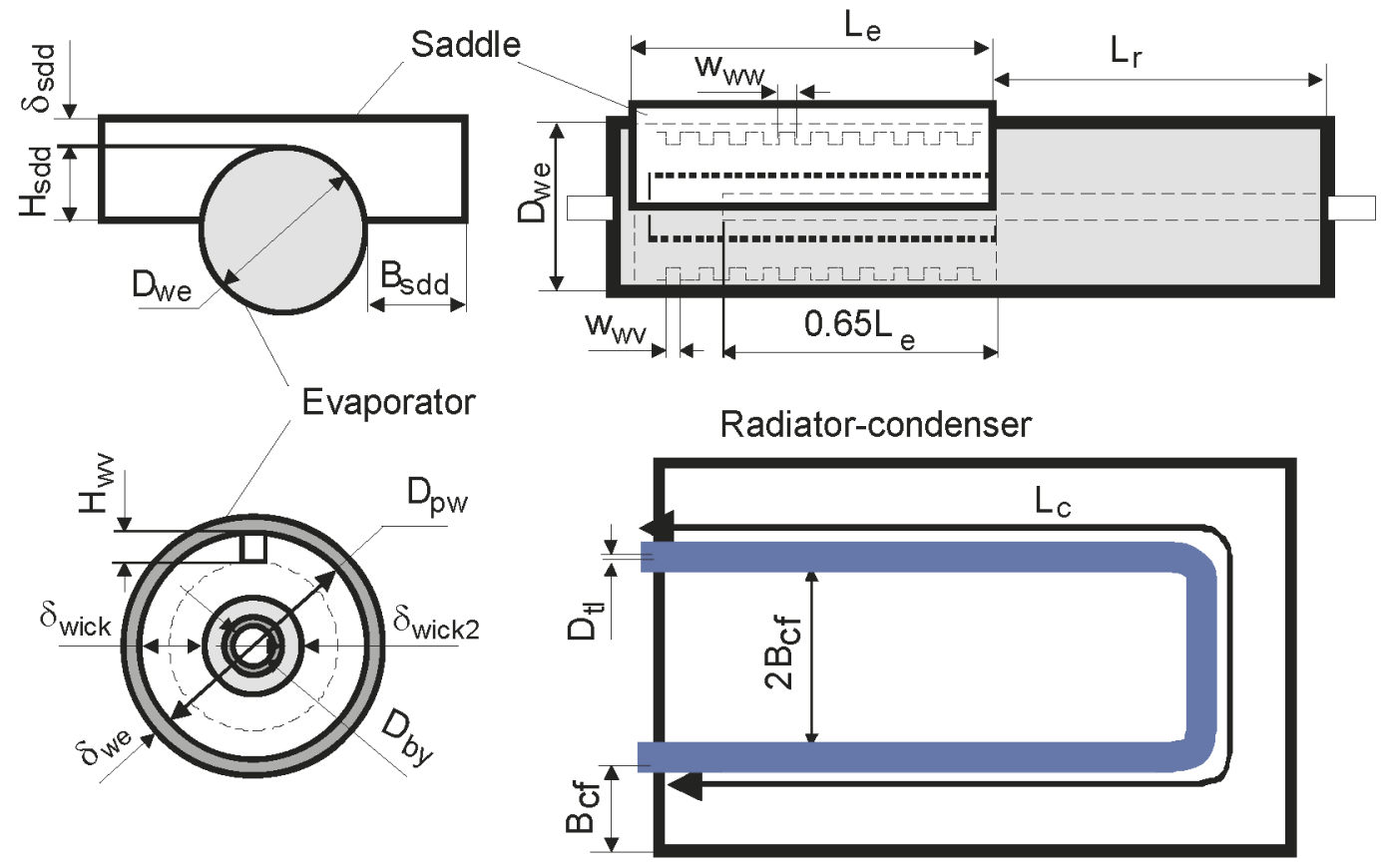

FIGURE 2. Main Design Dimensions.

An important item of the LHP design is the reservoir sizing and calculation of fluid charge amount. The corresponding parameters are defined through simultaneous consideration of two extreme operation cases: hot and cold. For each case the values of corresponding parameters $\left\{T_{s}, T_{a}, Q_{q}\right\}$ are different. Therefore, the core system (1-8) should be solved twice for each set of optimized design variables, resulting in two vectors $\bar{y}_{1}$ and $\bar{y}_{2}$. The different values of fluid densities and condenser openings for these two cases are used for the calculation of the reservoir volume and fluid inventory. 


\section{THE OPTIMIZATION PROCEDURE}

The criterion of the optimization is the minimal mass of the LHP system, including the saddle to the attached equipment and radiator plate. To take into account the heater power needed to heat up the reservoir on cold cases $\left(Q_{r}\right)$, an equivalent additional mass $\Delta M$ of the satellite power supply subsystem is used $\left(C_{h} \cong 0.1\right)$.

The problem's objective function can be written as:

$$
\min _{\bar{x}} M_{\Sigma}=M_{L H P}+\Delta M
$$

where $\Delta M=C_{h} Q_{r, 2}$. The vector of optimized design variables is composed by the following components:

$$
\bar{x}=\left\{L_{c}, B_{c f}, D_{t l}, L_{e}, \delta_{p w}, r_{p}, B_{s d d}, \zeta_{s d d}, Q_{r, 2}\right\}
$$

Other design variables, including reservoir length $L_{r}$, are recalculated on the base of the obtained optimized variables and vectors $\bar{y}_{i}$. The constraints of the optimization problem are the following:

(a) The temperature of the equipment should be within the limits:

$$
\mathrm{c} 1,2: T_{q, i} \leq T_{q \max }, \quad \mathrm{c} 3,4: T_{q, i} \geq T_{q \min } .
$$

(b) The capillary limit should not be violated in any case:

$$
\text { c5,6: } \Delta P_{\Sigma, i}+\Delta P_{p w, i} \leq \Delta P_{c a p, i},
$$

where $i$ is the operation mode number; here 1 or 2 are used for the hot or cold modes respectively.

The approach and structure of the optimization problem is similar to the ones used for a HP optimization in (Vlassov, de Sousa and Takahashi, 2006a). A global search metaheuristic, called Generalized Extremal Optimization, is used as the optimization tool. The algorithm is described in details in (de Sousa et al., 2003).

\section{RESULTS AND DISCUSSION}

The main input parameter ranges and values, as well as the boundary limits for optimized variables are summarized in Table 1. Other characteristics for the device are as follows: material of LHP- stainless steel; material of wick UHMW polyethylene; material of saddle and radiator plate - Aluminum alloy. The Table 2 shows the main optimal design parameters, derived from optimized variables, for different heat loads $Q_{q i}$, whereas Table 3 demonstrates the values of the same parameters for different length of transport lines.

Note that in all tables the optimal mass is the equivalent mass $\left(M_{\Sigma}\right)$ that includes the mass system increment $\Delta M$ related to power of the reservoir control heater, however in Figue 3(a) the LHP optimal design mass $\left(M_{L H P}\right)$ and power consumption (right y-axis) are shown separately.

For the given range of input data and LHP configuration, the best optimal equivalent mass of the assembly $\left(M_{\Sigma}\right)$ presents the ammonia LHP. Acetone optimal LHP has $12 \%$ to $25 \%$ mass characteristic worse and propylene LHP $29 \%$ to $42 \%$ worse. Propylene LHP has about twice power consumption for the reservoir heater against ammonia. It is notable that the acetone LHP does not need the control power for the considered cases. The last feature was also observed earlier on transient models and certainly is worth of a separate investigation. 
TABLE 1. Main Input Parameters and the Boundary Limits for the Optimized Variables.

\begin{tabular}{|c|c|c|c|c|c|c|}
\hline $\begin{array}{l}\text { Input } \\
\text { parameter }\end{array}$ & Values & $\begin{array}{l}\text { Input } \\
\text { parameter }\end{array}$ & Values & $\begin{array}{l}\text { Optimized } \\
\text { variable } \\
\end{array}$ & $\begin{array}{l}\text { Lower } \\
\text { limit }\end{array}$ & $\begin{array}{l}\text { Upper } \\
\text { limit }\end{array}$ \\
\hline $\mathrm{Q}_{\mathrm{q} 1}(\mathrm{~W})$ & $50 \ldots 250$ & $\delta_{\text {by }}(\mathrm{mm})$ & 0.4 & $\mathbf{L}_{\mathbf{e}}(\mathrm{mm})$ & 0.06 & 1.3 \\
\hline $\mathrm{Q}_{\mathrm{q} 2}(\mathrm{~W})$ & $10 \ldots 50$ & $\delta_{\text {wick2 }}(\mathrm{mm})$ & 1.5 & $\delta_{p w}(\mathrm{~mm})$ & 3.5 & 14 \\
\hline $\mathrm{T}_{\mathrm{q}, \max }(\mathrm{C})$ & 50 & $\mathrm{~W}_{\mathrm{WV}}(\mathrm{mm})$ & 2 & $\mathbf{r}_{\mathbf{p}}(\mu \mathrm{m})$ & 2 & 35 \\
\hline $\mathrm{T}_{\mathrm{q} \cdot \min }(\mathrm{C})$ & -20 & $\mathrm{w}_{\mathrm{ww}}(\mathrm{mm})$ & 2.3 & $\mathbf{B}_{\text {sdd }}(\mathrm{mm})$ & 10 & 20 \\
\hline $\mathrm{q}_{\mathrm{abs}}\left(\mathrm{W} / \mathrm{m}^{2}\right)$ & $178 \ldots 67$ & $\mathrm{H}_{\mathrm{WV}}(\mathrm{mm})$ & 2 & $\mathbf{Q}_{\mathrm{r} 2}(\mathrm{~W})$ & 0 & 20 \\
\hline $\mathrm{L}_{\mathrm{tl}}(\mathrm{m})$ & $1 \ldots 4$ & $\delta_{\mathrm{wf}}(\mathrm{mm})$ & 1 & $\mathbf{D}_{\mathrm{tl}}(\mathrm{mm})$ & 1.2 & 18 \\
\hline$\delta_{\mathrm{tl}}(\mathrm{mm})$ & 1 & $\xi_{\mathrm{co}, \min }$ & 0.05 & $\mathbf{L}_{\mathbf{c}}(\mathrm{m})$ & 0.5 & 9.0 \\
\hline $\mathrm{d}_{\mathrm{we}}(\mathrm{mm})$ & 1.4 & $\xi_{\mathrm{co}, \max }$ & 0.98 & $\mathbf{B}_{\mathbf{c f}}(\mathrm{mm})$ & 0.03 & 0.55 \\
\hline $\mathrm{D}_{\text {by }}(\mathrm{mm})$ & 3.2 & $\mathrm{~V}_{1, \mathrm{r}, \min } / \mathrm{V}_{\mathrm{r}}$ & 0.15 & $\zeta_{\text {sdd }}$ & 0.3 & 1.0 \\
\hline
\end{tabular}

TABLE 2. Optimal Design Parameters for Acetone/Ammonia/Propylene LHP at Different Heat Loads.

\begin{tabular}{llllll}
\hline & $\mathbf{Q}_{\mathbf{q} 1}=\mathbf{5 0 ,}, \mathbf{Q}_{\mathbf{q} 2}=\mathbf{1 0}$ & $\mathbf{Q}_{\mathbf{q} 1}=\mathbf{1 0 0}, \mathbf{Q}_{\mathbf{q} 2}=\mathbf{2 0}$ & $\mathbf{Q}_{\mathbf{q} 1}=\mathbf{1 5 0}, \mathbf{Q}_{\mathbf{q} 2}=\mathbf{3 0}$ & $\mathbf{Q}_{\mathbf{q} 1}=\mathbf{2 0 0}, \mathbf{Q}_{\mathbf{q} 2}=\mathbf{4 0}$ & $\mathbf{Q}_{\mathbf{q} 1}=\mathbf{2 5 0}, \mathbf{Q}_{\mathbf{q} 2}=\mathbf{5 0}$ \\
\hline $\mathrm{M}_{\Sigma}(\mathrm{kg})$ & $1.09 / 0.928 / 1.16$ & $2.30 / 2.04 / 2.64$ & $3.78 / 3.38 / 4.39$ & $5.61 / 4.92 / 6.58$ & $7.91 / 6.81 / 9.32$ \\
$\mathrm{~L}_{\mathrm{e}}(\mathrm{mm})$ & $103 / 90.3 / 128$ & $169 / 252 / 262$ & $243 / 305 / 453$ & $334 / 437 / 776$ & $450 / 468 / 1089$ \\
$\mathrm{~L}_{\mathrm{r}}(\mathrm{mm})$ & $42 / 15.1 / 72$ & $100 / 44.7 / 221$ & $141 / 107 / 469$ & $240 / 182 / 692$ & $414 / 215 / 1314$ \\
$\mathrm{D}_{\mathrm{pw}}(\mathrm{mm})$ & $16.8 / 14.0 / 14.0$ & $19.9 / 14.0 / 14.6$ & $24.3 / 14.0 / 14.0$ & $25.9 / 14.0 / 14.3$ & $24.6 / 17.4 / 14$ \\
$\mathrm{r}_{\mathrm{p}}(\mathrm{mm})$ & $7.5 / 3.5 / 13.8$ & $3.6 / 2.4 / 12.6$ & $3.9 / 2.0 / 6.8$ & $3.6 / 2.0 / 6.5$ & $2.8 / 2.4 / 5.1$ \\
$\mathrm{M}_{\mathrm{fluid}}(\mathrm{g})$ & $17.9 / 4.0 / 12.8$ & $50 / 11.4 / 36.4$ & $101 / 20.9 / 66.4$ & $180 / 33.3 / 102$ & $260 / 60 / 175$ \\
$\mathrm{~B}_{\mathrm{sdd}}(\mathrm{mm})$ & $10.0 / 10.0 / 10.0$ & $10.0 / 10.0 / 10.0$ & $10.0 / 10.4 / 10.0$ & $10.0 / 10.0 / 10.0$ & $10.2 / 10.6 / 10.0$ \\
$\mathrm{H}_{\mathrm{sdd}}(\mathrm{mm})$ & $13.6 / 16.7 / 10.4$ & $16.2 / 7.2 / 9.7$ & $17.0 / 13.9 / 7.7$ & $15.9 / 13.0 / 5.2$ & $18.0 / 15.0 / 5.4$ \\
$\mathrm{Q}_{\mathrm{r} 2}(\mathrm{~W})$ & $0 / 0.03 / 0.84$ & $0 / 1.0 / 3.3$ & $0 / 2.7 / 5.9$ & $0 / 4.3 / 9.0$ & $0 / 6.0 / 12.4$ \\
$\mathrm{D}_{\mathrm{t} 1}(\mathrm{~mm})$ & $2.7 / 1.2 / 2.9$ & $3.7 / 1.6 / 4.0$ & $4.5 / 2.0 / 4.8$ & $5.4 / 2.2 / 5.4$ & $5.9 / 2.6 / 6.4$ \\
$\mathrm{~L}_{\mathrm{c}}(\mathrm{m})$ & $1.35 / 1.48 / 1.28$ & $2.53 / 2.67 / 2.39$ & $3.48 / 4.52 / 3.40$ & $4.80 / 6.43 / 4.10$ & $6.32 / 7.82 / 5.36$ \\
$\mathrm{~B}_{\mathrm{cf}}(\mathrm{mm})$ & $81 / 70 / 80$ & $93 / 85 / 92$ & $114 / 78 / 107$ & $122 / 80 / 137$ & $100 / 93 / 140$ \\
$\xi_{\mathrm{co}, 2}$ & $0.36 / 0.56 / 0.57$ & $0.38 / 0.54 / 0.55$ & $0.37 / 0.52 / 0.52$ & $0.35 / 0.48 / 0.49$ & $0.30 / 0.45 / 0.46$ \\
\hline
\end{tabular}

The optimal design masses $\left(M_{L H P}\right)$ of propylene and acetone LHPs without power penalty are practically the same, and $18 \%$ to $30 \%$ higher than the ammonia LHP, respectively. It is interesting to note that the Liquid Transport Factor (well-known Figure of Merit for HP) indicates much more drastic differences: $9.5 \times 10^{10}, 3.2 \times 10^{10}, 0.29 \times 10^{10}$ for ammonia-acetone-propylene at $50{ }^{\circ} \mathrm{C}$, respectively.

The optimal lengths of evaporator are relatively high with respect to diameters. This is because the only factor limiting the design length is the hydraulic losses in the vapor grooves and bayonet. However, the hydraulic losses in the secondary wick could certainly contribute on the evaporator length limitation. Therefore, in order to the optimization model be more adequate, the hydraulic processes in the secondary wick should be included. It may be accomplished by completing these two steady-state modes (hot and cold) with a 3rd, transient mode, to be simultaneously tackled all together in the optimization loop. 
TABLE 3. Optimal Parameters for Acetone/Ammonia/Propylene LHP at Different Lengths of Transport Lines

\begin{tabular}{lllll}
\hline & \multicolumn{1}{c}{$\mathbf{L t l}=\mathbf{1} \mathbf{~ m}$} & \multicolumn{1}{c}{$\mathbf{L t} \mathbf{=} \mathbf{2} \mathbf{~ m}$} & \multicolumn{1}{c}{$\mathbf{L t l}=\mathbf{3} \mathbf{~ m}$} & \multicolumn{1}{c}{$\mathbf{L t} \mathbf{=} \mathbf{4} \mathbf{~ m}$} \\
\hline $\mathrm{M}_{\Sigma}(\mathrm{kg})$ & $2.30 / 2.03 / 2.61$ & $2.45 / 2.08 / 2.81$ & $2.61 / 2.15 / 2.94$ & $2.77 / 2.21 / 3.13$ \\
$\mathrm{~L}_{\mathrm{e}}(\mathrm{mm})$ & $160 / 176 / 318$ & $163 / 199 / 302$ & $174 / 228 / 330$ & $172 / 257 / 351$ \\
$\mathrm{~L}_{\mathrm{r}}(\mathrm{mm})$ & $93 / 54 / 251$ & $96 / 60 / 246$ & $103 / 61 / 293$ & $109 / 68 / 308$ \\
$\mathrm{D}_{\mathrm{pw}}(\mathrm{mm})$ & $20.4 / 13 / 13.1$ & $20.8 / 13 / 14.8$ & $21.0 / 13.1 / 13$ & $20.9 / 13 / 13.4$ \\
$\mathrm{r}_{\mathrm{p}}(\mathrm{mm})$ & $4.6 / 2.2 / 7.1$ & $3.7 / 2 / 10.4$ & $2.7 / 2 / 6.3$ & $2.9 / 2 / 6.6$ \\
$\mathrm{M}_{\mathrm{fluid}}(\mathrm{g})$ & $49 / 9.5 / 33$ & $60.3 / 11.6 / 48$ & $72.9 / 13.7 / 50$ & $84.8 / 16.1 / 60.9$ \\
$\mathrm{~B}_{\mathrm{sdd}}(\mathrm{mm})$ & $10.1 / 10.5 / 10$ & $10.2 / 10.0 / 10$ & $10.0 / 10.0 / 10$ & $10.4 / 10.5 / 10$ \\
$\mathrm{H}_{\mathrm{sdd}}(\mathrm{mm})$ & $16.9 / 14.4 / 5.1$ & $16.3 / 10.6 / 5.6$ & $17.2 / 12.2 / 5.4$ & $14.6 / 7.5 / 5.2$ \\
$\mathrm{Q}_{\mathrm{r} 2}(\mathrm{~W})$ & $0 / 1.1 / 3.2$ & $0 / 0.86 / 3.3$ & $0 / 0.74 / 3.2$ & $0 / 0.60 / 3.3$ \\
$\mathrm{D}_{\mathrm{t} 1}(\mathrm{~mm})$ & $3.7 / 1.55 / 3.7$ & $3.7 / 1.57 / 4.1$ & $3.8 / 1.60 / 4.0$ & $3.9 / 1.65 / 4.1$ \\
$\mathrm{~L}_{\mathrm{c}}(\mathrm{m})$ & $2.43 / 3.14 / 2.62$ & $2.46 / 3.25 / 2.42$ & $2.54 / 3.07 / 2.31$ & $2.44 / 3.04 / 2.24$ \\
$\mathrm{~B}_{\mathrm{cf}}(\mathrm{mm})$ & $99 / 71 / 83$ & $98 / 69 / 91$ & $93 / 70 / 97$ & $100 / 71 / 99$ \\
$\xi_{\mathrm{co}, 2}$ & $0.39 / 0.54 / 0.55$ & $0.36 / 0.54 / 0.55$ & $0.34 / 0.55 / 0.55$ & $0.33 / 0.55 / 0.55$ \\
\hline
\end{tabular}

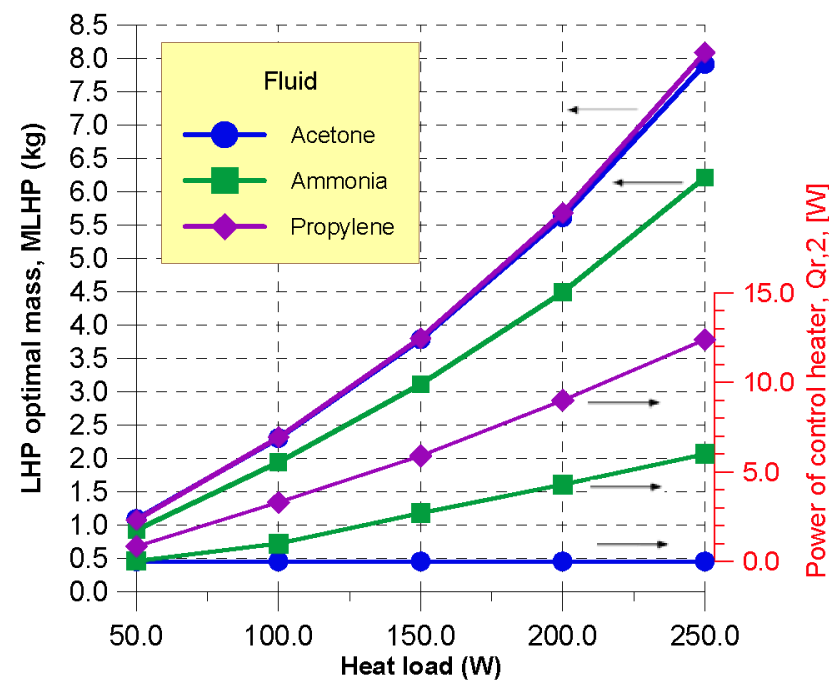

(a) - Optimal Mass $\left(M_{L H P}\right)$ and Power consumption $\left(Q_{r 2}\right)$

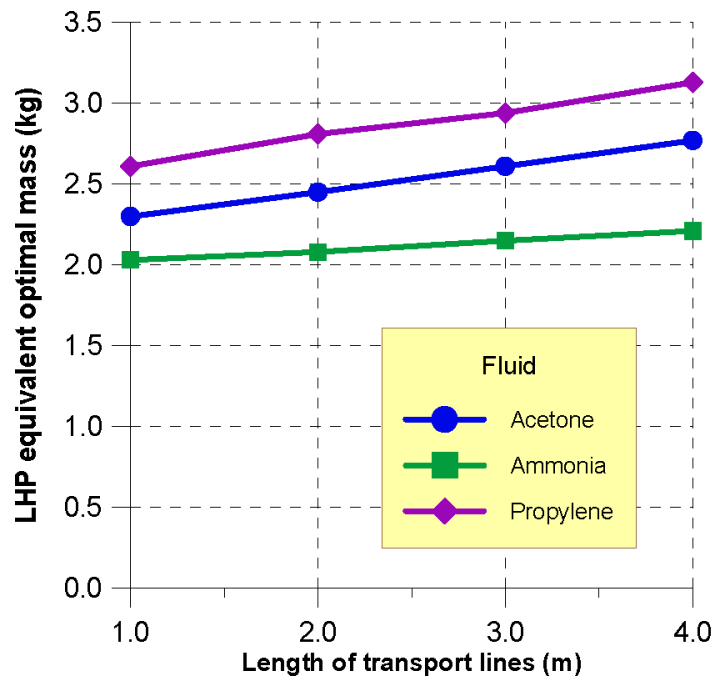

(b) - Equivalent Optimal Mass $\left(M_{\Sigma}\right)$ versus length $\left(L_{t l}\right)$

FIGURE 3. Optimal Mass $\left(M_{L H P}\right)$ and Power consumption $\left(\mathrm{Q}_{\mathrm{r} 2}\right)$ for Different Heat Loads $\left(Q_{q 1}\right)$.

\section{CONCLUSION}

The results confirm that using an optimization tool combined with a mathematical model, which is able to consider different LHP operational modes simultaneously, is a useful approach for the preliminary design of LHPs. Optimal parameters and characteristics are obtained automatically. New insights regarding design parameters interactions can be highlighted, leading to promising new developments. Trade-off studies, performed on this basic, provide very justified results due to the main inherent feature of the approach, by which the comparison is performed over alternatives with the design parameters optimized by a unique criterion. 


\section{NOMENCLATURE}
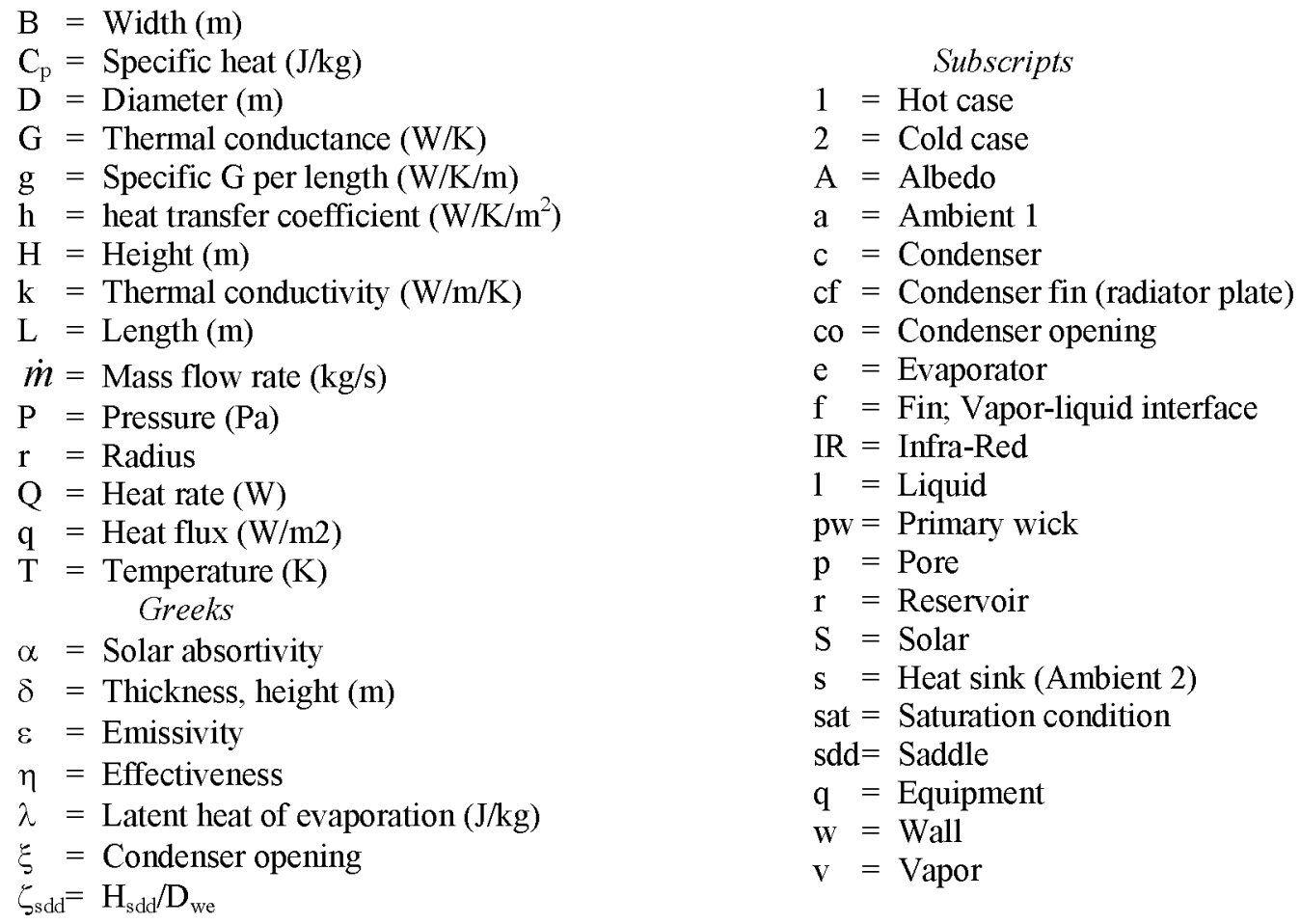

\section{REFERENCES}

Buz, V., and Goncharov, K., "Modeling of LHP Performances by Means of Specialized EASY Package Program," in proceedings of 12th IHPC, edited by Yu. Maidanik, May 19-24, Moscow, Russia, 2002, pp. 182-188.

Cullimore, B., and Baumann, J., "Steady-State and Transient Loop Heat Pipe Modeling," in proceedings of 30th ICES, edited by SAE Aerospace, July 10-13, Toulouse, France, 2000, 9 pp.

Goncharov, K., and Kolesnikov, V., "Development of Propylene LHP for Spacecraft Thermal Control," in proceedings of 12th IHPC, edited by Yu. Maidanik, Moscow-Kostroma-Moscow, Russia, 19-24 May, 2002, pp. 171-176.

Kaya, T., and Hoang, T.T., "Mathematical Modeling of Loop Heat Pipes and Experimental Validation," Journal of Thermophysics and Heat Transfer, 13, 314-320 (1999).

$\mathrm{Ku}$, J. "Operating Characteristics of Loop Heat Pipes," in proceedings of 29th ICES, edited by SAE Aerospace, Danvers, USA, July 12-15, 1999, pp. 1-16.

Maydanik, Y.F., "Loop Heat Pipe," Applied Thermal Engineering, 25, 635-657 (2005).

Nikitkin, M., and Cullimore, B., "CPL and LHP Technologies: What are the Differences, What are the Similarities," in proceedings of 28th ICES, edited by SAE Aerospace, July 13-16, Danvers, USA, 1998, 10 pp.

Riehl, R. R., and Santos, N., "Performance Improvement in Loop Heat Pipe Using Primary Wick with Circumferential Grooves," in proceedings of 36 th ICES, edited by SAE Aerospace, Norfolk, VA, July 17-20, 2006, 7 pp.

Riehl, R.R., and Vlassov, V.V., "Loop Heat Pipes Experimental Investigations, Mathematical Modeling and Development," in proceedings of VI Minsk Int. Seminar Heat Pipes, Heat Pumps, Refrigerators, Minsk, Belarus, 12-15 Sept., 2005,10 pp.

De Sousa, F.L, Ramos, F.M., Paglione, P., and Girardi, R.M., "New Stochastic Algorithm for Design Optimization," AIAA Journal, 41, 1808-1818(2003).

Vlassov, V.V., Schlitt, R., and Bondendieck, F., "Two-Level Modeling of Capillary Pumped Two-Phase Loops," in proceedings of Two-Phase 2003 International Two-Phase Thermal Control Technology Workshop, Noordwijk, Netherlands, Sept. 15-17, 2003.

Vlassov, V.V., and Riehl, R.R., "Modeling of a Loop Heat Pipe for Ground and Space Conditions," in proceedings of $35 t h$ ICES, edited by SAE Aerospace, 11-14 July, Rome, Italy, 2005, 12 pp.

Vlassov, V.V. de Sousa, F.L., and Takahashi, W.K., "Comprehensive Optimization of a Heat Pipe Radiator Assembly filled with Ammonia or Acetone," Int. Journal of Heat and Mass Transfer, 49, 4584-4595 (2006a).

Vlassov, V.V., and Riehl, R.R., "Modeling of a Loop Heat Pipe with Evaporator of Circumferential Vapor Grooves in Primary Wick," in proceedings of 36th ICES, edited by SAE Aerospace, July 17-21, Norfolk (VA), $2006 \mathrm{~b}, 11 \mathrm{pp}$. 
Copyright of AIP Conference Proceedings is the property of American Institute of Physics and its content may not be copied or emailed to multiple sites or posted to a listserv without the copyright holder's express written permission. However, users may print, download, or email articles for individual use. 